\title{
Dental Journal

\section{Effect of caffeine in chocolate (Theobroma cacao) on the alveolar bone mineral density in guinea pigs (Cavia cobaya) with orthodontic tooth movement}

\author{
Bramita Beta Arnanda, Sri Suparwitri and Pinandi Sri Pudyani \\ Department of Orthodontics, \\ Faculty of Dentistry, Universitas Gadjah Mada, \\ Yogyakarta - Indonesia
}

\begin{abstract}
Background: The benefits of chocolate have attracted significant attention from clinicians, especially the active compound of caffeine on bone metabolism. The bone density significantly affected the rate of tooth movement. Purpose: This study aims to analyse the effect of the dose and the duration of caffeine consumption in chocolate on alveolar bone mineral density in orthodontic tooth movement. Methods: Forty-eight male guinea pigs (Cavia cobaya) aged between 3-4 months and weighing 300-350 grams were divided into four groups (group A control, group B caffeine dose of $2.3 \mathrm{mg}$, group C caffeine dose of $3.45 \mathrm{mg}$, and group D caffeine dose of $4.6 \mathrm{mg}$ ). An open coil spring was applied to the mandibular inter-incisor with an orthodontic force of 35 grams. Guinea pigs were sacrificed using lethal doses of anaesthetics on days 0, 1, 7, and 14 after an orthodontic appliance installation. Mandibular alveolar bone mineral density in compression sites was analysed with an atomic absorption spectrophotometer (AAS). Experiment data results were analysed using two-way ANOVA with a 95\% degree of confidence. Results: Caffeine consumption with a dose of 4.6 mg on day 7 had the lowest alveolar bone mineral density and the highest was at a dose of $2.3 \mathrm{mg}$ on day 14 , but there were no differences between the dose groups, the duration groups and interactions between both of them ( $p>0.05)$. Conclusion: The consumption of caffeine in chocolate did not decrease the bone mineral density in the compression site of orthodontic tooth movement.
\end{abstract}

Keywords: orthodontic tooth movement, caffeine in chocolate, alveolar bone mineral density

Correspondence: Bramita Beta Arnanda, Department of Orthodontics, Faculty of Dentistry, Universitas Gadjah Mada. Jl. Denta I, Sekip Utara, Yogyakarta 55281, Indonesia. Email: bramita.beta.a@mail.ugm.ac.id

\section{INTRODUCTION}

Orthodontic treatment is one of the treatments in the field of dentistry that aims to obtain good dental structure and occlusal contact so that facial occlusion and aesthetic functions can be achieved as well as stable treatment results. ${ }^{1}$ However, orthodontic treatment periods are generally completed within a long time period since orthodontic devices are installed, which make it difficult to maintain oral hygiene, thus patients are more prone to caries and periodontal disease. ${ }^{2}$ Recently, natural materials have been used, developed, and produced for treatment purposes, one of which is to accelerate the movement of teeth when consuming caffeine in chocolate. ${ }^{3}$
Orthodontic tooth movement is influenced by many factors, one of them being bone density. ${ }^{4}$ Bone density is produced by the deposition of calcium and phosphorus, which act as hydroxyapatite during the bone mineralization process. ${ }^{5}$ Bone density can be analysed in the laboratory by measuring bone calcium levels. ${ }^{6}$ During orthodontic tooth movement, bone mineral density is regulated by osteoblasts and osteoclasts cells through interactions between the receptor activator of nuclear factor-ligand (RANKL), receptor activator of nuclear factor- $\mathrm{B}$ (RANK), and osteoprotegerin (OPG). Osteoclasts play a role in alveolar bone surface resorption by forming an acidic environment that causes bone demineralization and collagen matrix degradation, while osteoblasts play 
a role in bone formation through collagen secretion and glycoprotein to form osteoids. ${ }^{7}$ Osteoclasts are regulated by two major cytokines, namely macrophage colonystimulating factor (M-CSF) and RANKL produced by osteoblasts that bind to osteoclasts receptors, namely c-Fms and RANK. ${ }^{8}$

Chocolate (Theobroma cacao) is a processed cocoa product that has a diverse mixture of chemical compounds. Chocolate generally contains $55 \%$ fat, $17 \%$ carbohydrates, $11 \%$ protein, and the rest are tannins. The amount of caffeine in chocolate varies by the percentage of cocoa it contains, with $100 \%$ cocoa chocolate (unsweetened chocolate) containing around $240 \mathrm{mg}$ caffeine $/ 100 \mathrm{~g}$, $55 \%$ cocoa (bittersweet chocolate) containing $124 \mathrm{mg}$ caffeine $/ 100 \mathrm{~g}$, and $33 \%$ cocoa (milk chocolate) containing $45 \mathrm{mg}$ caffeine/100g. ${ }^{9}$ However, the effect of caffeine on bone metabolism is still being debated. The potential impact of caffeine on bone is its ability to increase calcium excretion, although in several studies using experimental animals it has not demonstrated a definitive effect of caffeine on bone. ${ }^{10}$

The biochemical role of caffeine is known to influence the process of bone apposition and resorption which is the basis of orthodontic tooth movement. ${ }^{11}$ Alhasyimi and Rosyida, ${ }^{3}$ stated that giving chocolate during the active period of orthodontic treatment has been shown to increase RANKL expression and decrease OPG on the compressed side that causes the acceleration of orthodontic tooth movement. This is due to the biochemical mechanism of the methylxanthine content, which is caffeine in chocolate, that can induce the release of RANKL by osteoblasts through the increased production of cyclic adenosine monophosphate (cAMP) so that there is an increase in the number of osteoclasts that will absorb bone. ${ }^{3}$

The effect of caffeine on bone metabolism depends on the dose consumed. An in vitro study demonstrated that by giving caffeine at a dose of $0.005-0.1 \mathrm{mM}$ for 24 hours can increase osteoclast cell differentiation through increased RANKL but does not affect the viability and differentiation of osteoblasts. An in vivo study of male guinea pigs with a caffeine administration of $22 \mathrm{mg} /$ day $(0.1 \%)$ and $44 \mathrm{mg} /$ day $(0.2 \%)$ for 20 weeks showed a decrease in bone mineral density through increased osteoclastogenesis. ${ }^{12}$ Research conducted by Lacerda et al. ${ }^{10}$ with an administration of caffeine at a dose equivalent to $240 \mathrm{~mL} /$ day in humans for 42 days showed an increase in urine calcium levels and a decrease in bone mineral density. According to the U.S. Food and Drug Administration (FDA), the allowable dose of caffeine is $100-200 \mathrm{mg}$ /day, whereas according to SNI 01-7152-2006 the maximum limit of caffeine in food and drink is $150 \mathrm{mg} /$ day or $50 \mathrm{mg} / \mathrm{serving} .{ }^{13,14}$

Decreased bone mineral density after caffeine consumption is known to be temporary. Patients who have high bone density such as hypoparathyroidism patients, athletes, and women with early menarche and who use oral contraceptives containing estrogen can utilize caffeine as an intermittent therapy during orthodontic treatment to restore the balance of bone resorption and apposition processes. $^{15-17}$

Based on the data that has been described, we felt the need to conduct research on the effect of caffeine on bone mineral density in relation to the evidence that caffeine consumption in chocolate can increase the osteoclast activity that plays a role in bone matrix resorption and the dissolution of mineral content in the alveolar bone on the compressed side, so it is expected to be used to accelerate the rate of orthodontic tooth movement. This study aims to analyse the effects of the dose and the duration of caffeine consumption from chocolate on alveolar bone mineral density in orthodontic tooth movement.

\section{MATERIALS AND METHODS}

All research procedures involving animals were performed according to in vivo experimental guidelines. An ethics permit was obtained from the Research Ethics Commission of the Faculty of Dentistry, Universitas Gadjah Mada with the number 00320/KKEP/FKG-UGM/EC/2019.

The experimental animal study was conducted at the Pharmacology and Clinical Pharmacy Laboratory, Faculty of Pharmacy, Universitas Gadjah Mada with 48 male guinea pigs weighing between 300-350 grams. Acclimatization was performed for one week to allow for their adaptation to shelter and food before being given treatment. Pellet-shaped food (Pollard) was given to minimize the likelihood of the bracket breaking. A drink for guinea pigs was given $\mathrm{ad}$ libitum. The temperature of the guinea pigs' maintenance room was $25^{\circ} \mathrm{C}$ with $50 \%$ humidity. The guinea pigs' lighting was 12 hours off (to simulate a night-like condition in the cage) and 12 hours on (to simulate a day-like condition in the cage). ${ }^{3}$ The guinea pig cages were made of PVC with a size of $60 \times 50 \times 40 \mathrm{~cm}$.

The caffeine dose used was based on a FDA recommended safe dose of 100-200 mg/day, which converted to a guinea pig dose resulted in a caffeine level of $2.3 \mathrm{mg}$ in 1.37 grams of chocolate; $3.45 \mathrm{mg}$ in 2.05 grams of chocolate, and 4.6 $\mathrm{mg}$ in 2.74 grams of chocolate (Hershey's natural cocoa unsweetened, USA). Experimental animals were randomly divided into 4 groups, each consisting of 12 animals which included a group A (control); a group B (caffeine dose of $2.3 \mathrm{mg}$ ); a group C (caffeine dose of $3.45 \mathrm{mg}$ ), and a group D (caffeine dose of $4.6 \mathrm{mg}$ ). These groups were then randomly divided into 4 subgroups according to the day of observation, i.e. days $0,1,7$, and 14 after orthodontic mechanical induction. Each subgroup consisted of three male guinea pigs. The number of samples was determined based on the Federer formula.

The installation of orthodontic devices was performed firstly by administering ketamine anaesthesia with a dose of $50 \mathrm{mg} / \mathrm{kg} \mathrm{BW}$ (Kepro, Netherland) and xylazine with a dose of $5 \mathrm{mg} / \mathrm{kg} \mathrm{BW}$ (Xyla, Netherland) intramuscularly on the lower thigh. The separator installation was carried out between the two mandibular incisors, followed by 
etching on the labial surface of the tooth and a 0.022 inch single wing straight Roth mini bracket (Marquis ${ }^{\mathrm{TM}}$, Ortho Technology®, USA) and a 0.016 inch stainless steel round wire and nickel-titanium open coil spring (American Orthodontics, USA) with a length of 1.5 times the interbracket distance paired between the brackets. The activated open coil spring provided a 35-gram strength measured using a tension gauge (Medkraft Orthodontics, USA) and was not reactivated after observing the $7^{\text {th }}$ day (Figure 1). The consumption of caffeine in chocolate was conducted from the beginning of the installation of the orthodontic devices for up to 14 days, when each cocoa powder was dissolved in $3 \mathrm{ml}$ of distilled water and given orally using a gastric tube twice a day in divided doses. $^{18}$

The guinea pigs were sacrificed with lethal doses of anaesthesia. Dissection was performed on the right lower alveolar bone until the distal of the right lower incisor and the root tip of the tooth could be removed. The samples that had been obtained were then calcined at $700^{\circ} \mathrm{C}$ for 24 hours aimed at removing the bone organic matrix and dissolving minerals, then dissolved in concentrated $\mathrm{HNO}_{3}$ at $80^{\circ} \mathrm{C}$ and diluted to obtain concentrations of $1-5 \mathrm{ppm}$. The samples obtained were analysed using the atomic absorption spectrophotometer (AAS) (Perkin Elmer 3110, USA) with a wavelength of $422.7 \mathrm{~nm}$ and a lamp current of $10 \mathrm{~mA}$ which was calculated in percentage units $(\%) .{ }^{19}$

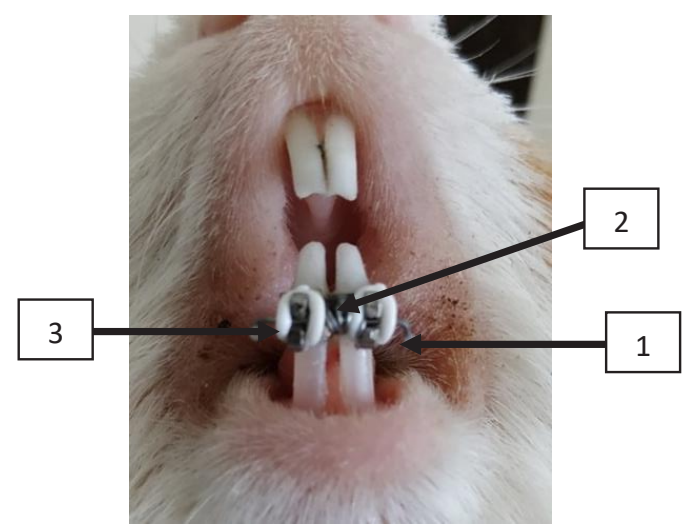

Figure 1. Installation of an open coil spring with a length of 1.5 times the distance of the lower incisors interbracket. (1) archwire 0.016" SS, (2) open coil spring, (3) power O.
The data obtained were presented as mean \pm standard deviation. The data were subjected to a test of normality and homogeneity and then were analysed using the two-way ANOVA test with a significance value of $95 \%$. Statistical analysis was processed with the SPSS 22.0 software system (IBM, Chicago, Illinois, USA).

\section{RESULTS}

The results of the measurement of the alveolar mandibular bone mineral density of the compressed side in guinea pigs are shown in Table 1, which showed that the lowest right compressed side of alveolar bone mineral density occurred in the caffeine $4.6 \mathrm{mg}$ dose group with a duration of caffeine consumption for 7 days. The highest of the alveolar bone mineral density of the right compressed side was seen in the treatment group with a dose of $2.3 \mathrm{mg}$ of caffeine and a duration of caffeine consumption in chocolate for 14 days.

The alveolar mandibular bone mineral density of the right compressed side in the control group appeared to increase on day 1 and decreased on days 7 to 14 , inversely proportional to the treatment group with a dose of caffeine consumption in chocolate $2.3 \mathrm{mg}$ which experienced a decrease on the $1^{\text {st }}$ day and gradually increase from the $7^{\text {th }}$ to $14^{\text {th }}$ days. The changes in the right compressed side of

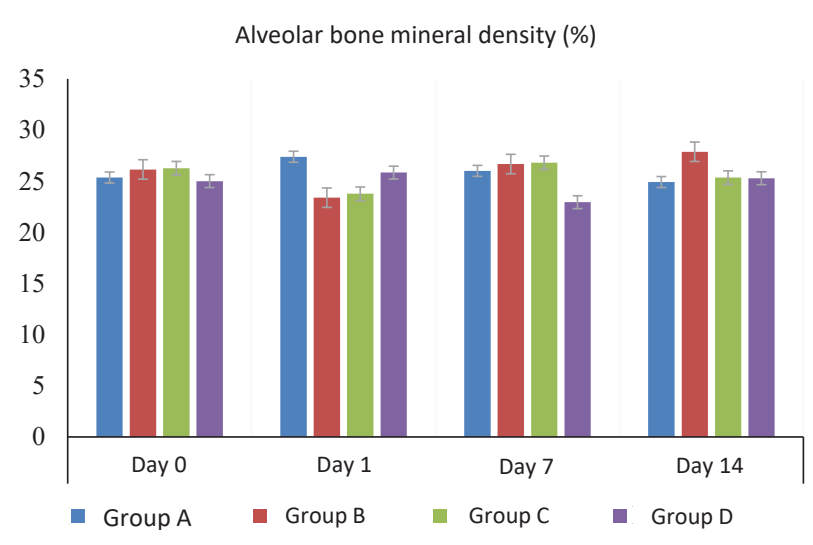

Figure 2. Alveolar bone mineral density changes in the compressed side of the mandible during the guinea pigs' orthodontic tooth movement.

Table 1. The mean values and standard deviations (SD) of the right compressed side of alveolar mandibular bone mineral from guinea pigs in orthodontic tooth movement in groups $\mathrm{A}, \mathrm{B}, \mathrm{C}$ and D

\begin{tabular}{lcccc}
\hline \multirow{2}{*}{ Group } & \multicolumn{4}{c}{ Mean \pm SD $(\%)$} \\
\cline { 2 - 5 } & Day 0 & Day 1 & Day 7 & Day 14 \\
\hline A & $25.36 \pm 0.78$ & $27.39 \pm 3.44$ & $26.01 \pm 1.49$ & $24.92 \pm 0.79$ \\
B & $26.15 \pm 0.16$ & $23.39 \pm 193$ & $26.68 \pm 1.45$ & $27.88 \pm 1.15$ \\
C & $26.27 \pm 2.99$ & $23.77 \pm 3.45$ & $26.80 \pm 0.96$ & $25.35 \pm 0.52$ \\
D & $25.01 \pm 3.25$ & $25.84 \pm 1.43$ & $22.95 \pm 1.35$ & $25.29 \pm 2.48$ \\
\hline
\end{tabular}

Note: A : Control group (distilled water); B: Treatment group with a caffeine dose of $2.3 \mathrm{mg}$; C: Treatment group with a caffeine dose of $3.45 \mathrm{mg}$; D: Treatment group with a caffeine dose of $4.6 \mathrm{mg}$ 
Table 2. The ANOVA test results of two pathways affecting the dose and the duration of caffeine consumption in chocolate on the mineral density of the depressed alveolar mandibular bone on the orthodontic tooth movement of guinea pigs

\begin{tabular}{lcc}
\hline Variables & $\mathrm{F}$ & $\mathrm{p}$ value \\
\hline Dose & 0.892 & 0.456 \\
Duration & 0.314 & 0.815 \\
Dose*Duration & 1.921 & 0.086 \\
\hline Note: The difference is not significant if $\mathrm{p}>0.05$ &
\end{tabular}

alveolar mandibular bone mineral in the treatment group with a caffeine dose of $3.45 \mathrm{mg}$ on days 0 to 7 days were the same as the caffeine dose group of $2.3 \mathrm{mg}$ but decreased on the $14^{\text {th }}$ day. The changes in the alveolar bone mineral density in the treatment group with a caffeine dose of 4.6 $\mathrm{mg}$ from day 0 to day 7 were the same as in the control group but increased on day 14 (Figure 2).

The research data were then analysed using the two-way ANOVA test to determine differences between groups of doses, between groups of duration and interactions between groups of doses, and doses of caffeine consumption in chocolate. The two-way ANOVA test results (Table 2) showed that there was no significant difference in the right compressed side of alveolar mandibular bone mineral density between group A (without caffeine consumption in chocolate), group B (caffeine dose of $2.3 \mathrm{mg}$ ), group $\mathrm{C}$ (caffeine dose of $3.45 \mathrm{mg}$ ), and group D (caffeine dose of $4.6 \mathrm{mg}$ ). It also showed no significant difference in the mineral density of the right compressed side of alveolar mandibular bone between $0,1,7$, and 14 days of observation and no significant difference in interaction between the dose group and the duration of caffeine consumption in chocolate $(p>0.05)$.

\section{DISCUSSION}

The results of this study on the effect of the dose and the duration of caffeine consumption in chocolate on the mineral density of the right compressed side of alveolar mandibular bone showed a decrease in calcium levels in the bones in the control group starting from day 1 to day 14 . This indicates that there has been remodeling of the alveolar bone that was dominated by bone resorption. This is in line with research conducted by Wang et al. ${ }^{7}$ in mice using a closed coil spring which shows a decrease in bone mineral density on days 3 to 14 and returns to normal on day 28 . A decrease in bone mineral density in the control group is likely due to the mechanical induction of orthodontics to stimulate osteoblasts to release RANKL and M-CSF which then binds to c-Fms and RANK on osteoclast precursors so that osteoclast differentiation and activation occurs for bone resorption. ${ }^{8}$
Alveolar bone mineral density in the caffeine consumption group in chocolate at a good dose of $2.3 \mathrm{mg}$, $3.45 \mathrm{mg}$, and $4.6 \mathrm{mg}$ appears to vary or fluctuate. This is probably caused by differences in the systemic conditions of experimental animals used in the study. Systemic conditions, especially in the liver, affect the process of caffeine metabolism in the body. Caffeine metabolism in the liver is determined by the cytochrome P450 1A2 (CYP1A2) enzyme which varies by subject. Subjects with high CYP1A2 enzyme levels have a fast caffeine metabolic rate so that it has a small effect on the body. Conversely, low CYP1A2 enzyme levels will reduce the metabolic rate and maintain caffeine concentration in the body longer so that it will have a significant effect on body tissues. ${ }^{20}$ The ups and downs phenomenon of alveolar bone mineral density also correspond to the Yerkes-Dodson caffeine activity curve. Rozenek et al. ${ }^{21}$ stated that in the Yerkes-Dodson curve, the effect of caffeine has an optimum limit to achieve efficient performance which means that at certain doses of caffeine the effect will increase at a certain point, then the effect will again decrease and these dynamics are influenced by the sensitivity of the subject to caffeine which is determined by genetic factors and the quality of health and the rate of metabolism of caffeine in the body.

A decrease in the right-sided lower jaw alveolar bone mineral density showed no significant differences between the dose groups, between the duration and interaction of doses, and the duration of caffeine consumption in chocolate. This indicates that the consumption of caffeine in chocolate does not cause a decrease in the mineral density of the alveolar bone in the orthodontic movement of guinea pig teeth. The effect of caffeine on bone metabolism is still being debated. The potential impact of caffeine on the bone is its ability to increase calcium excretion in urine which causes a decrease in bone calcium levels, but several studies using experimental animals have not demonstrated the definitive influence of caffeine on bone. This is in line with research conducted by $\mathrm{Yi}$ et al. ${ }^{22}$ which stated that alveolar bone mineral density in the caffeine group at a dose of $25 \mathrm{mg} / \mathrm{kg} \mathrm{BW}$ and controls induced by orthodontic strength were not significant differences. This is due to the presence of a number of confounding factors, including differences in dosage, the duration of consumption, the method of administration and type, and the age range of experimental animals used. ${ }^{22}$

According to research conducted by Hallstrom, ${ }^{23}$ caffeine has a biphasic dose-dependent effect. An increased excretion of calcium in the urine only occurs over a short duration (initial acute rise) in the consumption of caffeine with a low concentration of $0.005-0.1 \mathrm{mM}$ (equivalent to $0.97-19.4 \mathrm{mg}$ ). Then caffeine will quickly induce differentiation osteogenic from primary adipose-derived stem cells and bone marrow stromal cells, thereby returning calcium levels to baseline. The effect of caffeine on bones also depends on the concentration of the caffeine metabolite, namely paraxanthine. The concentration of caffeine consumed is relatively the same as the amount 
of paraxanthine concentration in the body, so with a low dose of caffeine the concentration of paraxanthine is also low. ${ }^{11,12,23}$

Gavrieli et al. ${ }^{24}$ stated that the effect or potential of caffeine on the body is proportional to the subject's body weight and height, which means that the greater the body weight, the dose of caffeine needs to be increased. The results of the study were insignificant, possibly due to not weighing the subject so that the caffeine dose in chocolate that was given did not follow the weight gain of experimental animals during the study causing a decrease in the potential for caffeine in alveolar bone tissue.

In line with research by Hallstrom ${ }^{23}$ and $\mathrm{Yi}$ et al. ${ }^{22}$ a significant decrease in alveolar bone mineral density is likely caused by the source of caffeine used in this study of chocolate. The caffeine content in 5 grams of Hershey's chocolate powder is $8.4 \mathrm{mg}$ which is lower than the caffeine content in coffee or tea, so that the effect of caffeine on decreasing bone calcium levels is not optimal. In addition, the route or method of administration can also affect the amount of active concentration of caffeine on the body's physiological response. ${ }^{25}$ The oral administration of gavage tends to have a slow onset of therapeutic effect, causing the caffeine potential to decrease due to metabolic processes in the gastrointestinal tract and liver.

The insignificant research results may also be caused by the difficulty of controlling the type of tooth movement during the administration of orthodontic force induction. According to Kirschneck et al. ${ }^{26}$ experimental studies on experimental animals tend to occur primarily with tipping movements and to a lesser degree bodily tooth movement that causes uneven distribution of pressure in the periodontal tissue. This results in differences in biological responses to the strength of orthodontics given. Research by Ahn et al. ${ }^{27}$ stated that in the movement of tipping, there is a greater accumulation of pressure in the alveolar crest region so that more resorption occurs in the area. Yu et al. $^{28}$ added that the decrease in alveolar bone mineral density is greater in the cervical region (alveolar crest) than in the apical region. In line with the study of Ahn et al. ${ }^{27}$ and $\mathrm{Yu}$ et al. ${ }^{28}$ an insignificant decrease in bone mineral density is likely caused by alveolar bone used as samples are alveolar bone that covers the cervical to apical regions so that calcium levels dissolved by osteoclast activity are only modest because osteoclast activity is less dominant in the intermediates and apical regions.

Based on research conducted by Alihasyimi and Rosyida, ${ }^{3}$ consumption of caffeine in chocolate $2.7 \mathrm{mg}$ (Hershey's, USA) in male Wistar mice can accelerate tooth movement through increased RANKL expression and decrease OPG on days 0,1 , and 7 on side stress. This indicates that the dose and the duration of the study used is $2.3 \mathrm{mg}$ to $4.6 \mathrm{mg}$ for 14 days safe for consumption and provides a positive impact or correlation because it can accelerate the orthodontic movement of guinea pigs but does not cause decreased alveolar bone mineral density.
Based on the results of the study, it can be concluded that the consumption of caffeine in chocolate did not decrease in the bone mineral density of the lower jaw alveolar bone in guinea pigs (Cavia cobaya) with orthodontic tooth movement.

\section{ACKNOWLEDGEMENT}

This research is fully supported by the Hibah Penelitian Dana Masyarakat grant, Faculty of Dentistry, Universitas Gadjah Mada, Republic of Indonesia, for the fiscal year 2019 (contract no. 4319/UN1/FKG1/Set.KG1/PT/2019).

\section{REFERENCES}

1. Ardhana W. Identifikasi perawatan ortodontik spesialistik dan umum. Maj Kedokt Gigi Indones. 2013; 20: 1-8.

2. Yi J, Zhang L, Yan B, Yang L, Li Y, Zhao Z. Drinking coffee may help accelerate orthodontic tooth movement. Dent Hypotheses. 2012; 3(2): 72-5.

3. Alhasyimi AA, Rosyida NF. Cocoa administration may accelerate orthodontic tooth movement by inducing osteoclastogenesis in rats. Iran J Basic Med Sci. 2019; 22(2): 206-10.

4. Graber L, Vanarsdall R, Vig K, Huang G. Orthodontics: current principles and techniques. 6th ed. Philadelphia: Mosby; 2017. p. 133.

5. Kranioti EF, Bonicelli A, García-Donas JG. Bone-mineral density: clinical significance, methods of quantification and forensic applications. Res Reports Forensic Med Sci. 2019; 9: 9-21.

6. Song L. Calcium and bone metabolism indices. Adv Clin Chem. 2017; 82: 1-46.

7. Wang C, Cao L, Yang C, Fan Y. A novel method to quantify longitudinal orthodontic bone changes with in vivo Micro-CT data. J Healthc Eng. 2018; 2018: 1-8.

8. Kim JH, Kim N. Signaling pathways in osteoclast differentiation. Chonnam Med J. 2016; 52: 12-7.

9. Temple JL, Bernard C, Lipshultz SE, Czachor JD, Westphal JA, Mestre MA. The safety of ingested caffeine: A comprehensive review. Front Psychiatry. 2017; 8: 80.

10. Lacerda SA, Matuoka RI, Macedo RM, Petenusci SO, Campos AA, Brentegani LG. Bone quality associated with daily intake of coffee: A biochemical, radiographic and histometric study. Braz Dent J. 2010; 21(3): 199-204.

11. Shirazi M, Vaziri H, Salari B, Motahhari P, Etemad-Moghadam S, Dehpour AR. The effect of caffeine on orthodontic tooth movement in rats. Iran J Basic Med Sci. 2017; 20(3): 260-4.

12. Liu SH, Chen C, Yang R Sen, Yen YP, Yang YT, Tsai C. Caffeine enhances osteoclast differentiation from bone marrow hematopoietic cells and reduces bone mineral density in growing rats. J Orthop Res. 2011; 29(6): 954-60.

13. Fahmi Arwangga A, Raka Astiti Asih IA, Sudiarta IW. Analisis kandungan kafein pada kopi di desa Sesaot Narmada menggunakan Spektrofotometri UV-VIS. J Kim. 2016; 10: 110-4.

14. Food and Drug Administration. Highly concentrated caffeine in dietary supplements: Guidance for industry. US Dep Heal Hum Serv. 2018; (April): 1-8.

15. Rubin MR, Bilezikian JP. Hypoparathyroidism: clinical features, skeletal microstructure and parathyroid hormone replacement. Arq Bras Endocrinol Metabol. 2010; 54(2): 220-6.

16. National Institutes of Health. Osteoporosis: Peak bone mass in women. NIH Osteoporos Relat Bone Dis Natl Resour Cent. 2015; (Juni): 1-2.

17. Kacprzak A, Strzecki A. Methods of accelerating orthodontic tooth movement: A review of contemporary literature. Dent Med Probl. 2018; 55(2): 197-206. 
18. Herniyati, Narmada IB, Devi LS. Caffeine increases PGE2 levels at compression and tension areas during orthodontic tooth movement. Int J Chem. 2018; 11(6): 177-82.

19. Figueiredo M, Cunha S, Martins G, Freitas J, Judas F, Figueiredo H. Influence of hydrochloric acid concentration on the demineralization of cortical bone. Chem Eng Res Des. 2011; 89: 116-24.

20. Langer JW. Genetics, metabolism and individual responses to caffeine. Coffee Heal Inst Sci Inf coffee. 2018; : 1-13.

21. Rozenek EB, Górska M, Wilczyńska K, Waszkiewicz N. In search of optimal psychoactivation: Stimulants as cognitive performance enhancers. Arh Hig Rada Toksikol. 2019; 70(3): 150-9.

22. Yi J, Yan B, Li M, Wang Y, Zheng W, Li Y, Zhao Z. Caffeine may enhance orthodontic tooth movement through increasing osteoclastogenesis induced by periodontal ligament cells under compression. Arch Oral Biol. 2016; 64: 51-60.

23. Hallström H, Wolk A, Glynn A, Michaëlsson K. Coffee, tea and caffeine consumption in relation to osteoporotic fracture risk in a cohort of Swedish women. Osteoporos Int. 2006; 17(7): 1055-64.
24. Gavrieli A, Karfopoulou E, Kardatou E, Spyreli E, Fragopoulou E, Mantzoros CS, Yannakoulia M. Effect of different amounts of coffee on dietary intake and appetite of normal-weight and overweight/ obese individuals. Obesity. 2013; 21(6): 1127-32.

25. Hines RM, Khumnark M, Macphail B, Hines DJ. Administration of micronized caffeine using a novel oral delivery film results in rapid absorption and electroencephalogram suppression. Front Pharmacol. 2019; 10: 983.

26. Kirschneck C, Bauer M, Gubernator J, Proff P, Schröder A. Comparative assessment of mouse models for experimental orthodontic tooth movement. Sci Rep. 2020; 10: 12154.

27. Ahn HW, Moon SC, Baek SH. Morphometric evaluation of changes in the alveolar bone and roots of the maxillary anterior teeth before and after en masse retraction using cone-beam computed tomography. Angle Orthod. 2013; 83(2): 212-21.

28. Yu JH, Huang HL, Liu CF, Wu J, Li YF, Tsai MT, Hsu JT. Does orthodontic treatment affect the alveolar bone density? Med (United States). 2016; 95(10): 1-10. 